\title{
Long-term treatment with antidepressants in primary care
}

\author{
Are sub-therapeutic doses still being used?
}

\author{
Imad M. Ali
}

\begin{abstract}
A postal survey of 222 patients receiving long-term antidepressants in a training general practice showed that the majority were GHQ-12 cases and $62 \%$ of respondents reported moderate or severe depressive symptoms on the BDI-13. Although these patients recelved significantly higher doses than those reporting few or no symptoms, only $40 \%$ were prescribed at least a therapeutic antidepressant dose. All patients reporting mild, moderate or severe depressive symptoms consulted their general practitioner significantly more frequentty than those without symptoms and the content of these consultations suggested that the general practitioners were aware of these patients' psychological morbidity. Monitoring and appropriate management of patients recelving long-term antidepressants could lead to reduction in morbidity and consultation rate.
\end{abstract}

Low dose antidepressant prescription is still common in primary care (Tyrer, 1978; Donoghue \& Tylee, 1996; Donoghue et al, 1996; McDonald et al, 1996) despite lack of evidence of its efficacy (Thompson \& Thompson, 1989). The Defeat Depression Campaign (Paykel \& Priest, 1992) focuses on improving the recognition and treatment of depressive illness and accordingly recommends prescription of antidepressants in therapeutic doses. Since its launch there has been a 33\% increase in the antidepressant prescribing rate and an increase in the proportion of patients receiving a therapeutic antidepressant dose in primary care. These changes are, however, almost entirely accounted for by a much greater increase in prescription for selective serotonin reuptake inhibitors (SSRIs) as compared to other antidepressants; of those patients prescribed a tricyclic antidepressant for depression, the likelihood of receiving a therapeutic dose has not been affected by the Defeat Depression Campaign (Donoghue et al, 1996).

Little is known about morbidity in recipients of long-term antidepressants in general practice; this study surveys the prevalence of depressive symptoms in this group and aims to clarify any association between the antidepressant dose prescribed and symptom severity, in order to ascertain whether continued low dose antidepressant therapy can be justified. An analysis is also made of consultation rates to clarify whether the burden on the general practitioner (GP) could be reduced by effective management of this patient group.

\section{The study}

The study was carried out in a modern, computerised, urban, teaching, general practice serving 9800 patients in Merthyr Tydfil, South Wales (population 60 000). The practice computer was used to identify patients aged over 17 years who had received antidepressants for a depressive illness for at least 12 months continuously. Patients were excluded if the indication for antidepressant treatment was not recorded, if antidepressants were prescribed for indications other than a depressive illness or if the primary diagnosis was schizophrenia, bipolar-affective disorder or dementia. For each patient, demographic characteristics and the class, duration and dose of antidepressant prescription, in terms of amitriptyline equivalents, was noted (Table 1).

The total number of routine and urgent GP consultations over the previous 18 months was noted. However, consultations which only resulted in a comment that a sickness certificate had been renewed were excluded from the total consultation count. This reduced the possible confounding effect caused by the wide variation in the frequency with which patients received their certificates (between once-monthly and once-yearly).

Consultations were further assessed by noting their content. Those which resulted in an entry in the records of only psychological symptoms, such as 'anxiety', 'insomnia' or 'depression', were counted as consultations for exclusively psychological complaints. Biological symptoms of depression such as anorexia, anergia and weight 
Table 1. Equivalent doses of antidepressants

\begin{tabular}{ll}
\hline Antidepressant & Dally dose $(\mathbf{m g})$ \\
\hline Amitriptyline & 150 \\
Amoxapine & 150 \\
Clomipramine & 150 \\
Dothiepin & 150 \\
Doxepin & 150 \\
Fluoxetine & 20 (40 $\mathrm{mg}$ fluoxetine=250 $\mathrm{mg}$ amitriptyline) \\
Fluvoxamine & 150 \\
Imipramine & 150 \\
Iprindole & 90 \\
Lofepramine & 210 \\
Maprotiline & 110 \\
Mianserin & 60 (20 $\mathrm{mg}$ mianserin=100 mg amitriptyline, 30-40 mg mianserin=125 mg amitriptyline) \\
Nortriptyline & 45 \\
Paroxetine & 30 \\
Phenelzine & 45 \\
Protriptyline & 30 \\
Sertraline & 150 \\
Trazodone & 300 \\
Tranylcypromine & 20 \\
\hline
\end{tabular}

loss were included under 'psychological' complaints as long as it was clear from the records that the GP considered them as such, and not as indicative of a physical illness.

Consultations resulting in even one physical complaint being entered in the records (whether this was accompanied by psychological complaints or not) were not counted in this category but were included within the total consultation rate.

Patients were sent the General Health Questionnaire, 12-item version (GHQ-12) and the shortened Beck Depression Inventory (BDI-13), to assess psychiatric caseness and the severity of depressive symptoms respectively (Beck et al, 1974; Goldberg, 1978). A second mailing was performed after 10 weeks to non-respondents. Comparison was made between the group reporting severe symptoms and those reporting no symptoms, as a control group, to clarify any relationship between symptom severity, the dose of antidepressant prescribed and the GP consultation rate.

The study was approved by the local research ethics committee and permission was granted by the GPs for the author (who had recently completed a year's GP training with the practice) to examine the records of patients who had received long-term antidepressants. Patients were invited by the senior partner of the practice to participate in this study by returning the questionnaires which were mailed to them.

\section{Findings}

Two hundred and sixty-three patients had received antidepressant treatment continuously for greater than 12 months. Forty-one patients did not meet criteria for inclusion into the study, leaving a target population of 222 patients, or $2.3 \%$ of the practice list.

The majority comprised middle-aged women (mean age 53 years, range 19-88, s.d. 15, and $3: 1$ female to males), most of whom received a tricyclic antidepressant $(73 \%)$ for a mean duration of 3.4 years. The mean amitriptyline equivalent daily dose prescribed was only $97 \mathrm{mg}$ (range 10-400 mg, s.d. 58); furthermore only $33 \%$ of patients received at least $125 \mathrm{mg}$ of amitriptyline equivalents daily, the recommended minimum therapeutic dose for depressive illness (Paykel \& Priest, 1992).

The group as a whole consulted their GP frequently; the mean exclusively psychological consultation rate was 3.2 per 18 months and the mean total consultation rate was 10.8 per 18 months. This was 1.5 times the mean total consultation rate for a similar age and gender matched sample of 100 patients within the practice who were not in receipt of antidepressants.

\section{Response rate to the postal survey}

One hundred and seventy-three (78\%) of the 222 patients on long-term antidepressant treatment returned questionnaires after two mailings. There was no statistically significant difference between the group returning questionnaires, and those not doing so, in terms of their mean age $(t=1.07, P=0.28)$, gender distribution $\left(\chi^{2}=0.53\right.$, d.f. $=1, P=0.46$ ), duration of antidepressant prescription ( $t=0.81, P=0.42)$, prescribed mean amitriptyline equivalent dose $(t=0.42, P=0.67)$ 
and the total consultation rate with the GP $(t=0.98, P=0.32)$.

\section{Analysis of responders to the postal survey}

The GHQ-12 and BDI-13 scores correlated well with one another (Pearson's correlation coefficient value of $0.747(P=0.001))$. The majority of patients $(77 \%)$ could be classed as psychiatric cases, using a GHQ-12 threshold score of two and the mean BDI-13 score was 10.8 (range 032. s.d.=7.1). The BDI-13 was scored in the standard way so that patients were classed into four groups reporting either 'no', 'mild', 'moderate' or 'severe' depressive symptoms, hereafter also referred to as severity groups $1,2,3$ and 4 respectively. Of 171 respondents, $42(25 \%)$ reported no depressive symptoms, 23 (14\%) reported mild, $58(34 \%)$ reported moderate and $48(28 \%)$ severe depressive symptoms. Thus overall, $62 \%$ reported either moderate or severe symptoms despite long-term antidepressant treatment.

These results of the analysis of patients with different symptom severity according to the BDI13 score are shown in Table 2.

\section{Age}

Those who report more severe symptoms are significantly younger than those with no symptoms; the mean age was 59.9, 58.1, 51.1 and 48.4 years in severity groups $1,2,3$ and 4 respectively (one-way analysis of variance, $F$ ratio $=7.67, P=0.0001$ ).

\section{Gender}

Although there is a higher proportion of men in the 'moderate' and 'severe' symptom groups as compared to that in the 'no' and 'mild' symptom groups, this difference does not achieve statistical significance $\left(\chi^{2}=0.99\right.$, d.f. $\left.=3, P=0.80\right)$.

\section{Antidepressant prescribing}

A significantly higher amitriptyline equivalent daily dose is prescribed for patients in severity group 4 compared to severity group 1 ( $t=2.16$, $P=0.033)$ and group $2(t=2.99, P=0.004)$, and there is a significantly higher dose prescribed for patients in group 3 as compared to those in group $2(t=2.6, P=0.01)$. Thus, a greater proportion of patients in the moderate and severely depressed groups receive therapeutic antidepressant doses (36.2 and $43.7 \%$ respectively), as compared to that in the no or mild symptom groups (26.2 and $17.4 \%$ respectively).

\section{Consultations with GPs}

These results of consultations with GPs are shown in Table 3. Patients not reporting symptoms attended a mean of 7.8 times (in the previous 18 months), of which 1.4 were for exclusively psychological complaints, while those with mild, moderate or severe symptoms (data grouped together) attended a mean of 12.2 times, of which 3.6 were for psychological complaints. There were significantly more total consultations with the GP in groups 2,3 and 4 as compared to group $1(P=0.015, P=0.001$ and $P=0.006$, respectively) and therefore patients with any symptoms of depression (mild, moderate or severe) consulted their GP more frequently than patients with no symptoms. Of these total consultations, there were significantly more exclusively psychological consultations made by patients with moderate and severe symptoms as compared to patients with no symptoms $(P=0.001)$.

\section{Comment}

This study of long-term antidepressant use in a single training general practice may not be representative of other practices. Indeed the proportion of this practice's list on long-term antidepressant prescription is between 2-4 times that in other studies (Catalan et al, 1988; Kerr. 1991; Harborne, 1992), however the evidence is that this prescription rate is appropriate for this particular population.

The practice serves 9800 patients from Merthyr Tydfil, which is one of the most disadvantaged areas in South Wales. Sixty-four point five per cent of the practice list attracts deprivation payments, the majority (two-thirds) of these being at the maximum level. This study therefore concerns a practice population which experiences relative socio-economic adversity, which

Table 2. Demographic characteristics and pattern of antidepressant prescription, $n=171$

\begin{tabular}{llccc}
\hline Severity group & $\begin{array}{l}\text { Severity } 1 \\
\text { (none) }\end{array}$ & $\begin{array}{l}\text { Severity 2 } \\
\text { (mild) }\end{array}$ & $\begin{array}{l}\text { Severity 3 } \\
\text { (moderate) }\end{array}$ & $\begin{array}{l}\text { Severity 4 } \\
\text { (severe) }\end{array}$ \\
\hline Mean age (years) & 59.9 & 58.4 & 51.1 & 48.4 \\
Per cent men & 21.4 & 21.7 & 29.3 & 25.0 \\
Mean duration of antidepressant prescription (years) & 3.5 & 3.2 & 3.3 & 3.8 \\
Mean equivalent amitriptyline dose (mg/day) & 82.5 & 73.3 & 105 & 111 \\
Per cent recelving 125+ mg/day & 26.2 & 17.4 & 36.2 & 43.7 \\
\hline
\end{tabular}


Table 3. GP consultation rate within previous 18 months and GHQ-12 scores, $n=171$

\begin{tabular}{lcccl}
\hline Severtity group & $\begin{array}{l}\text { Severity I } \\
\text { (no) }\end{array}$ & $\begin{array}{l}\text { Severity 2 } \\
\text { (mild) }\end{array}$ & $\begin{array}{l}\text { Severity 3 } \\
\text { (moderate) }\end{array}$ & $\begin{array}{l}\text { Severity 4 } \\
\text { (severe) }\end{array}$ \\
\hline Mean total consultations & 7.8 & 12.8 & 12.6 & 11.5 \\
Mean psychological consultations & 1.4 & 2.8 & 3.9 & 3.6 \\
Per cent psychological consultations & 17.9 & 21.8 & 30.9 & 31.3 \\
Mean GHQ-12 score & 1.1 & 4.3 & 6.7 & 9.7 \\
Per cent GHQ-12 cases (GHQ=2+) & 36 & 77 & 88 & 98 \\
\hline
\end{tabular}

one would therefore expect to be associated with high levels of psychiatric morbidity (Brown \& Harris, 1978; Platt et al, 1990) and thus a high antidepressant prescribing rate would be appropriate if the morbidity were being correctly identified by the GPs - that this does seem to be the case is shown by the high prevalence of moderate-severe depressive symptoms identified in the study population (62\%).

The study achieved a good response rate $(78 \%)$ to the postal survey and the population size (222 patients) allowed useful conclusions to be drawn. The GHQ-12 and BDI-13 are established instruments and the results showed that these questionnaires correlated highly with one another, were acceptable to patients, and more importantly, that there was no significant difference in the characteristics measured between responders and non-responders to the survey.

The most important and striking finding was that, of long-term antidepressant recipients, twothirds report moderate or severe depressive symptoms, and the majority of these are GHQ12 cases, despite a mean duration of antidepressant treatment of over three years. Furthermore, only $40 \%$ of those patients who reported either moderate or severe depressive symptoms re ceived a therapeutic antidepressant dose which is disappointingly low.

To the author's knowledge this is the first study to compare rates of therapeutic antidepressant prescription between patients reporting varying degrees of depressive symptoms; the findings are, however, consistent with other UK studies of antidepressant prescription in primary care. Earlier single general practice studies of patients receiving long-term antidepressants (for any indication) showed that only $22-33 \%$ of patients received a therapeutic dose of the antidepressant (Catalan et al, 1988; Kerr, 1991), whereas more recent larger studies of patients being treated for depression have reported figures of 53-60\% (Donoghue \& Tylee. 1996; Donoghue et al, 1996). These findings suggest that a regular review of symptoms and of the dose of antidepressant is required; the continued use of sub-therapeutic doses is ineffective in relieving symptoms and cannot be justified.
Twenty-five per cent of patients responding to the survey reported no symptoms on the BDI-13 and equally this group of patients also requires review to assess whether the benefit of continued treatment (prophylaxis of future episodes) outweighs its disadvantages (side-effects, risk of overdose and monetary costs).

The potential benefit to the GP of the effective treatment of depressed patients in terms of reduced workload is suggested by the consultation rates. Patients on long-term antidepressants consulted at around twice the national average (Royal College of General Practitioners et al. 1982) even when consultations exclusively for sickness certificates were excluded. As expected, patients reporting symptoms on the BDI-13 (mild, moderate or severe) made a significantly greater number of total consultations than patients not reporting symptoms, and they also had significantly more exclusively psychological consultations, thus suggesting that the GPs are at least aware of their patients' emotional illhealth. Although it is unclear what proportion of these consultations were patient rather than GP initiated, the findings do suggest that the burden on the GP would reduce if these patients were successfully treated and became symptom-free.

Thus this study has shown substantial depressive symptoms in long-term antidepressant recipients and emphasises the under-use of therapeutic antidepressant doses in this population of high consulters. There is clearly a need for regular review of the management of this patient group, and the BDI-13 or GHQ-12 could be employed as tools to assist the GP in this monitoring.

\section{Acknowledgements}

I thank Dr B. Wookey and all the other partners and staff of Pontcae surgery, Merthyr Tydfil. My thanks also to Dr M. Kerr (Ely Hospital, Cardiff), Professor A. Farmer and Professor P. McGuffin (University of Wales College of Medicine) for their help with this research and for their advice on earlier drafts of this paper. This work attracted a research donation from Dista Products. 


\section{References}

BECK A. T., RIAL, W. Y. \& RICKELS, K. (1974) Short form of depression inventory: cross validation. Psychological Reports. 34. 1184

BROWN, G. W. \& HARRIS, T. (1978) Social Origins of Depression: A Study of Psychiatric Disorder in Women. London: Tavistock.

Catalan, J., Gath, D. H., Bond, A. et al (1988) Genera practice patients on long-term psychotropic drugs - a controlled investigation. British Journal of Psychiatry. 162. 399-405.

Donoghue, J. M. \& TrueE, A. (1996) The treatment of depression: prescribing patterns of antidepressants in primary care in the UK. British Journal of Psychiatry. 168. 164-168.

Donoghue, J., TYlee, A. \& Wildgust, H. (1996) Crosssectional database analysis of antidepressant prescribing in general practice in the United Kingdom. 1993-5. British Medical Journal, 313, 861-862.

GoldBerg, D. P. (1978) Manual of the General Health Questionnaire. Windsor: Nfer-Nelson.

HARBORNE, G. (1992) Supervision of repeat antidepressant prescribing in general practice (letter). British Journal of Psychiatry. 161, 428

KERR, M. P. (1991) Antidepressant prescribing in general practice - how long can this go on? Psychiatric Bulletin. 15. 281-283.

MCDONALD, T. M., MCMAHON, A. D., REID. I. C., et al (1996) Antidepressant drug use in primary care: a record linkage study in Tayside, Scotland. British Medical Journal, 313, 860-861.

PAYKel, F. S. \& PRIEST, R. G. (1992) Recognition and management of depression in general practice: a consensus statement. British Medical Joumal, 306. 1198-1202.

Platt, S., MarTin, C. \& Hunt, S. (1990) The mental health of women with children living in deprived areas of Great Britain: the role of living conditions, poverty and unemployment. In The Public Health Impact of Mental Disorder, (eds D. P. Goldberg \& D. J. Tantam). Toronto, ON: Hogrefe and Huber.

Royal College of General Practitioners, Office of POPULATION CENSUSES AND SURVEYS \& DEPARTMENT OF HEALTH (1992) Morbidity Statistics From General Practice, 1981-1982. Third National Study: Socioeconomic Analyses. London: HMSO.

THOMPSON, C. \& THOMPSON, C. M. (1989) The prescribing of antidepressants in general practice. II: A placebo controlled trial of low-dose dothiepin. Human Psychopharmacology. 4, 191-204.

TYRER. P. (1978) Drug treatment of psychiatric patients in general practice. British Medical Journal, 2. 1008-1010.

Imad M. Ali, Senior Registrar, Talygarn, County Hospital Site, Griffithstown, Pontypool, Gwent NP4 5YA

\title{
Books from Gaskell
}

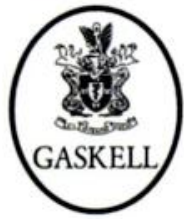

\section{Mental Disorders in China}

\author{
English Version Editors: John E. Cooper \& Norman Sartorius
}

This is the first available account in English of the results of the 1982 Chinese Epidemiological Survey of Mental Disorder. It is the only nationwide Chinese study to involve modern methods of case assessment and is uniquely large and interesting; 12 centres in different parts of China studied a rural and an urban sample of 500 households each, giving a total sample of 51982 persons. The use of the Present State Examination in the survey allows the symptomatic basis of diagnoses, such as neurasthenia, to be examined. The results indicate that the prevalence of schizophrenia is similar to that found recently in other countries, but that the prevalence of other mental disorders may be lower. Readers may also be interested to purchase Mental Health Care in China, published in 1995, price $\mathrm{E} / 2.50$.

- Price $f \mid 5.00 \bullet$ I28pp. • I996• ISBN 090224 I 93 I

Available from good bookshops and from the Publications Department, Royal College of Psychiatrists, 17 Belgrave Square, London SWIX 8PG (Tel. 017I-235 235I, extension 146) 